\title{
Dijital Sinir Tamir Sonuçları ve Etkileyen Faktörler
}

\author{
Digital Nerve Repair Results and Affecting Factors
}

\author{
Bilgehan ÇATAL
}

İstanbul Medipol Üniversitesi Tıp Fakültesi Ortopedi ve Travmatoloji Anabilim Dalı, İstanbu

\begin{abstract}
Çalışmamızın amacı dijital sinir onarımı sonrası başarının objektif olarak değerlendirilmesi ve başarıyı etkileyen faktörlerin incelenmesidir. Çalışmaya 3 yıllık bir süre içinde tedavi edilen ve kontrole gelen 51 hastadaki 73 dijital sinir onarımı retrospektif olarak dahil edilmiștir. Hastaların yașı, cinsiyeti, mesleği, dominant eli, yaralanan dijital sinirin lokalizasyonu, yaralanma ile ameliyat arasında geçen süre, sinir yaralanmasına eşlik eden diğer el yaralanmaları, yaralanma tipi ve sigara içme alışkanlıkları kayıt edilmiştir. İyileşmenin değerlendirilmesinde birincil olarak iki nokta diskriminasyon testi kullanılmış bunun yanında monofilament, diyapazon, ten, kavrama ve çimdikleme testleri de uygulanmıștır. Çalışmamızda sinir onarımlarının \%84.9'unda iki nokta diskriminasyon testine göre iyi ve çok iyi olarak değerlendirilmiştir. Monofilament testine göre \%72.6 normal ve azalmıș hafif dokunma olarak bulunmuștur. Diyapazon testinde pozitiflik oranı \%89 iken ten testine göre hastaların \%86.3'ü istenen seviyede idi. Yaş, sigara kullanımı, yaralanma tipi ve duyusal iyileşme arasında negatif bir ilişki vardı. Dijital sinir tamirleri yüksek iyileşme potansiyeli ile tatminkâr sonuçlar vermektedir. Hastanın yaşı, sigara kullanımını ve yaralanma tipi dijital sinir tamir sonuçlarını kötü olarak etkilemekle birlikte, yaş dışında kalan epidemiyolojik özellikler, ameliyatta kadar geçen süre, takip süresi, eşlik eden diğer el yaralanmaları ve yaralanmanın olduğu parmak iyileşme üzerine anlamlı bir etkiye sahip değildir.
\end{abstract}

Anahtar Kelimeler: Dijital Sinir, İyileşme, Tamir

\section{Giriş}

Dijital sinirler yaralanmaları el cerrahisi pratiğinde sık rastlanan bir durumdur. Dijital sinirler en sik yaralanan periferik sinirdir (1). Basit bir kesiden ciddi el yaralanmalarına kadar birçok sebep dijital sinir hasarına neden olabilir. Hasar sonrası onarım sağlanmadığında el fonksiyonlarının önemli bir parçası olan dokunarak tanıma (taktil gnostizm) kaybı olmaktadır. Özellikle başparmak, 2. ve 5. parmak için önemli olan koruyucu duyu kaybolmakta buna bağlı 1sı yaralanmalarında artma gözükebilmekte ayrıca çimdikleme (pinching) işlevi de yapılamamaktadır. Bunun yanı sıra sinir kesisinin uçlarında gelişebilecek nörinomlar ağrıya sebep olup hastanın yaşam kalitesini düşürmektedir (2). Elin beceriklilik gerektiren ince motor işlevlerinin yerine getirilmesi içinde dijital sinirlere önemli görevler düşmektedir. Eldeki becerikli hareketin

\begin{tabular}{ll}
\hline Bilgehan ÇATAL & $\begin{array}{l}\text { ORCID No } \\
\text { 0000-0002-4883-4317 }\end{array}$ \\
Başvuru Tarihi / Received: & 08.09 .2020 \\
Kabul Tarihi / Accepted : & 18.12 .2020 \\
Adres / Correspondence : & Bilgehan ÇATAL \\
İstanbul Medipol Üniversitesi Tip Fakültesi Ortopedi ve \\
$\begin{array}{l}\text { Travmatoloji Anabilim Dalı, İstanbul } \\
\text { e-posta / e-mail } \quad: \quad \text { drbilgehancatal@ yahoo.com }\end{array}$ \\
\hline
\end{tabular}

\begin{abstract}
The aim of this study is to evaluate the success of the digital nerve repair and to examine the factors affecting recovery. Seventy-three digital nerve repairs in 51 patients who were treated over a 3-year period were retrospectively included in the study. Patients' age, gender, profession, dominant hand, localization of the injured digital nerve, the time between injury and surgery, other hand injuries accompanying nerve injury, injury type and smoking habits were recorded. In the evaluation of the nerve recovery, two point discrimination test was used primarily, besides monoflament, tuning fork, skin, grip and pinch tests were also applied. In this study, $84.9 \%$ of nerve repairs were evaluated as good and very good according to the two-point discrimination test. According to the monoflament test, $72.6 \%$ was normal and decreased light touch. The positivity rate in the tuning fork test was $89 \%$ and according to the skin test, $86.3 \%$ of the patients were at the desired level. There was a negative relationship between age, smoking, injury type, and sensory recovery. Digital nerve repairs provide satisfactory results with high healing potential. Patient age, smoking, and type of injury negatively affect digital nerve repair results. Epidemiological features other than age, time to surgery, follow-up time and other accompanying hand injuries do not have a significant effect on healing.
\end{abstract}

Keywords: Digital Nerve, Recovery, Repair

sağlanabilmesi için motor ve duyunun sentezi gerekmektedir (3).

Sinir iyileşmesini etkileyen çeşitli faktörler mevcuttur. Hastanın yaşı, yaralanma ile tamir arasında geçen süre, sinirin nasıl yaralandığı ve nasıl tamir edildiği gibi değişkenler sinir iyileşmesini etkileyen faktörlerdir (4).

Çalıșmamızın amacı dijital sinir onarımı sonrası başarının objektif olarak değerlendirilmesi ve başarıyı etkileyen faktörlerin incelenmesidir.

\section{Gerec ve Yöntem}

Çalışmamız için, İstanbul Medipol Üniversitesi Girişimsel Olmayan Klinik Araştırmalar Etik Kurulu'ndan 03.09.2020 tarih ve 675 sayılı yazı ile izin alınmıştır. Çalışmamıza İzmir Kâtip Çelebi Üniversitesi Atatürk Eğitim ve Araştırma Hastanesi Ortopedi Kliniği'nce 3 yıllık bir süre içinde tedavi edilen kontrole gelen 51 hastadaki 73 dijital sinir dahil edilmiştir. Çalışmaya yaralanma şekli, zamanı ve eşlik eden diğer el yaralanmalarına bakılmaksızın kliniğimizde cerrahi mikroskop ile uç uça epinöral olarak tamir edilen dijital sinir yaralanmaları retrospektif olarak dahil edilmiştir. Tüm hastalara ameliyat sonrasi atelleme yapılarak 3 hafta immobilizasyon uygulandı, postoperatif 1 . günde pasif parmak egzersizleri başlandı ve 
immobilizasyonun sonlandirılmasını takiben aktif parmak egzersizleri ile rehabilitasyona devam edilmiştir. 10 yaş altı pediatrik hastalar, mental yetersizliği olan erişkin hastalar, takip süresi 6 aydan kısa olan hastalar, uç uça epinöral tamir dışında bir teknik ile sinir onarımı yapılan hastalar, standart rehabilitasyon programina uymayan hastalar ve tümöre bağlı dijital sinir yaralanması olan hastalar çalışmaya dahil edilmemiştir.

Hastaların yaşı, cinsiyeti, mesleği, dominant eli, yaralanan dijital sinirin lokalizasyonu, yaralanma ile ameliyat arasında geçen süre, sinir yaralanmasına eşlik eden diğer el yaralanmaları, yaralanma tipi ve sigara içme alışkanlıkları kayıt edilmiștir. Çalışmamızda ilk 24 saat içinde yapılan tamirler primer, 2. gün - 17. gün arasında yapılanlar gecikmiş, 17. günden sonra yapılanlar ise sekonder sinir tamiri olarak kabul edildi. İyileşmeyi değerlendirmek için iki nokta diskriminasyon testi, Semmes Weinstein monofilament testi, diyapazon testi, ten testi, yaralanan ve sağlam elin pinchmetre ve dinamometre ile ölçüm değerleri kullanıldı.

İki nokta diskriminasyon ölçümünde DiskCriminator (Baseline Evalution Industry, White Plains NY 10602 USA) aleti kullanıldı. En geniş aralıktan en dar aralığa kadar yapılan ölçümlerde tek nokta hissedilen en dar aralık ölçüm değeri olarak kaydedildi. Kaydedilen değerler Mackinnon sınıflaması kullanılarak çok iyi (6 mm ve altı), iyi (7$15 \mathrm{~mm})$, zayıf $(15-30 \mathrm{~mm})$ ve yok $(>30 \mathrm{~mm})$ olarak değerlendirildi (5). Semmes Weinstein monofilament testi beş ayrı monofilament ile gerçekleştirildi (Baseline Evalution Industry, White Plains NY 10602 USA). Monofilamentler, inceden kalında doğru plastik deformasyon oluşturmadan tutulup olgunun hissettiği değer kaydedildi. Diyapazon testi için $256 \mathrm{~Hz}$ frekans aralığındaki diyapazon cihazı (Bmed Device) kullanıldı. Sert bir cisim ile diyapazona vurulup titreştirildikten sonra ilgili dijital sinirin innerve ettiği parmağın tırnak yatak proksimali hizasına yerleştirildi ve hastanın titreşimi hissedip hissetmemesine göre pozitif ve negatif olarak değerlendirildi. Ten testi yapılırken hastaların dijital sinir tamiri yapılan parmaklarına ve kontralateral sağlam parmaklarının aynı tarafına pamuk tutuldu. Sağlam taraftaki hissetme gücünün 10 puan olarak kabul edilmesi ve dijital sinir tamiri yapılmış taraftaki pamuğu hissetme gücünü buna göre 1'den 10'a kadar puanlandırmaları istendi ve hastaların beyan ettiği değer kayıt edildi. Kavrama testi için dinamometre cihazı (Baseline Evalution Industry, White Plains NY 10602 USA) kullanıldı. Ölçümler üç tekrarlı olarak yapıldı, aritmetik ortalaması kayıt edildi. Ölçümler omuz addüksiyonda, dirsek 90' fleksiyonda, ön kol nötral pozisyonda yapıldı. Birim olarak kilogram alındı. Çimdikleme testi pinchmetre cihazı (Baseline Evalution Industry, White Plains NY 10602 USA) ile yapılmıştır. Ölçümler üç tekrarlı olarak yapıldı, aritmetik ortalaması kayıt edildi.
Değerlendirme testlerinin sonuçları eşlik eden el yaralanmalarına, hastanın sigara içme alışkanlığına, hastanın takip süresine, ameliyat ile yaralanma arasında geçen süreye hastanın yaşına ve yaralanma tipine göre incelenerek dijital sinir iyileşmesinde etkili olan faktörler araştırıldı.

Çalışmanın istatistikleri SPSS 15.0 sürümü (SPSS Inc, Chicago, IL) kullanılarak yapıldı. Parametrik değerler ortalama, en düşük ve en yüksek değer olarak non-parametrik değerler ise yüzde olarak verildi. Grupların karşılaştırılmasında Pearson Ki-Kare testi kullanıldı ve $\mathrm{p}<0.05$ anlamlı olarak kabul edildi.

\section{Bulgular}

Çalışmaya dahil edilen 51 hastanın yaş ortalamas1 31.7 (11-55) ve \%81'ini 3. ve 4. dekattaki hasta grubu oluşturmakta idi. Hastaların 40'1 (78\%) erkek $11^{\prime} i$ ise $(22 \%)$ kadındı. Hastaların ortalama takip süresi 13.1 (6-50) ay idi. Yaralanma ile ameliyat arasından geçen süre ortalama 7.9 (1-49) gün idi. Yetmiş üç dijital sinir kesisinin 47'sine (64.3\%) primer sinir onarımı, 15'ine (20.5\%) gecikmiş sinir onarımı ve 11 'ine (15\%) sekonder sinir onarımı uygulandı. 51 hastanın 33 'ü (64.7\%) yaralanmadan sonraki ilk 12 saat içinde ameliyat edildi.

Hastaların tamamının dominant eli sağ taraf idi ve yaralanmaların 33\%'ü dominant elde 67\%'si nondominant elde gerçekleşmiştir. Çalışmamızda en sık yaralanan dijital sinir $22 \%$ ile non-dominant elin başparmağı idi. 51 hastadaki 73 dijital sinir kesisinin eşlik eden diğer el yaralanmalarına ve hasarlanma şekline göre ayrıntısı Tablo 1'de verilmiştir.

Hastaların iki nokta diskriminasyon değerlendirme ortalamaları $7.5(2-25) \mathrm{mm}$ idi ve Mackinnon Sinıflamasına göre sinir onarımlarının 29'u (39.7\%) çok iyi, 33'ü (45.2\%) iyi, 11'i (15.1\%) zayıf olarak dğerlendirildi. Monofilament testi değerlendirmesine göre sinir onarımlarının 32'si (43.9\%) normal, 21 'inde $(28.7 \%)$ azalmış hafif dokunma, 12 'sinde (16.5\%) azalmış koruyucu duyu kayb1, 5'inde (6.8\%) koruyucu duyu kaybı ve 3 'ünde (4.1\%) derin basınç hissi sonucu bulundu. Hastaların diyapazon testi sonuçlarına göre, 65 sinir onarımında $(89 \%)$ test pozitif, $8(11 \%)$ sinir onarımında ise test negatif olarak bulundu. Ten testi değerlendirmesinde genel ortalamas1 7.55 (1-10) idi. 63 sinir onarımında $(86.3 \%)$ değerler 10 üzerinden 5 ve üstü, 10 (13.7\%) sinir onarımında ise değerler 5 'in altında idi.

Eşlik eden yaralanmaya göre hastaların değerlendirme test sonuçları karşılaştırıldığında eşlik eden yaralanmanın iki nokta diskriminasyon $(p=0.067)$ ve monofilament testinde $(p=0.062)$ istatiksel bir farka sebep olmadığ fakat diyapazon testinde $(\mathrm{p}=0.031)$ anlamlı olarak fark yaratığı ve eşlik eden yaralanmanın şiddeti artıkça diyapazon testi pozitifliğinin azaldığı görüldü. Sigara içme alışkanlığı olan hastalarda $(\mathrm{n}=22)$ iki nokta 
Tablo 1. Dijital sinir yaralanmalarının eşlik eden diğer el yaralanmalarına ve yaralanmanın şekline göre sinıflandırılması

\begin{tabular}{lcccc}
\hline \multicolumn{1}{c}{ Eşlik eden yaralanma } & Hasta sayısı & Hasarlanan sinir & Temiz kesi & Ezilme yaralanması \\
\hline İzole sinir kesisi & $15(\% 29.4)$ & $15(\% 20.5)$ & $14(\% 28)$ & $1(\% 1.9)$ \\
Sinir + Tendon Kesisi & $25(\% 49)$ & $33(\% 45.2)$ & $22(\% 43.1)$ & $3(\% 5.9)$ \\
Sinir + Tendon kesisi + Parmak Kırığı & $4(\% 77.8)$ & $11(\% 15.1)$ & 0 & $4(\% 7.9)$ \\
Parmak Amputasyonu & $7(\% 13.8)$ & $14(\% 19.2)$ & $2(\% 3.4)$ & $5(\% 9.8)$ \\
Toplam & $\mathbf{5 1 ( \% 1 0 0 )}$ & $\mathbf{7 3 ( \% 1 0 0 )}$ & $\mathbf{3 8}(\% \mathbf{7 4 . 5})$ & $\mathbf{1 3}(\% \mathbf{2 5 . 5})$ \\
\hline
\end{tabular}

Tablo 2. Dijital sinir iyileşmesine etki eden faktörler

\begin{tabular}{|c|c|c|c|c|c|c|c|c|}
\hline \multirow[t]{2}{*}{ Eşlik eden yaralanma } & \multirow[t]{2}{*}{$\begin{array}{l}\text { Ortalama İki } \\
\text { Diskriminasyon } \\
(\mathrm{mm})\end{array}$} & \multirow[t]{2}{*}{$\begin{array}{r}\text { Nokta } \\
\text { Sonucu }\end{array}$} & \multicolumn{2}{|c|}{$\begin{array}{l}\text { Monofilament Testi } \\
\text { (Normal ve Azalmış } \\
\text { Duyu Olan Sinir } \\
\text { Yüzdesi) }\end{array}$} & \multicolumn{2}{|c|}{$\begin{array}{l}\text { Diyapazon Testi } \\
\text { (Pozitif Hasta Yüzdesi) }\end{array}$} & \multicolumn{2}{|c|}{$\begin{array}{l}\text { Ortalama Ten Testi } \\
\text { Puanı } \\
\text { (Ortalama) }\end{array}$} \\
\hline & & & & & & & & \\
\hline - İzole sinir & $5.2 /$ çok iyi & & $\% 80$ & & $\% 100$ & & 7.3 & \\
\hline Sinir + tendon kesisi & $6.3 /$ çok iyi & & $\% 78.7$ & & $\% 94$ & & 7.8 & \\
\hline - $\quad$ Sinir + tendon kesisi + parmak kırığ 1 & $9.1 /$ iyi & $\mathrm{p}=0.067$ & $\% 45.5$ & $\mathrm{p}=0.067$ & $\% 63.6$ & $\mathrm{p}=\mathbf{0 . 0 3 1}$ * & 5.5 & $\mathrm{p}=0.181$ \\
\hline - $\quad$ Parmak ampütasyonu & $11.2 /$ iyi & & $\% 57$ & & $\% 64.2$ & & 6.2 & \\
\hline \multicolumn{9}{|l|}{ Sigara alıșkanlığı } \\
\hline - İçiyor & 8.7/ iyi & $\mathrm{p}<0.001^{*}$ & $\% 64.2$ & $\mathrm{p}=0.321$ & & & & \\
\hline - $\quad$ İçmiyor & $6.7 /$ çok iyi & & $\% 76.2$ & & & & & \\
\hline \multicolumn{9}{|l|}{ Takip süresi } \\
\hline$-\quad<12$ ay & 7.2 / iyi & $\mathrm{p}=0.076$ & $\% 74$ & $\mathrm{p}=0.051$ & $\% 93.7$ & $\mathrm{p}=0.26$ & 8.2 & $\mathrm{p}=0.227$ \\
\hline$\geq 12$ ay & $7.9 /$ iyi & & $\% 69$ & & $\% 83$ & & 7.3 & \\
\hline \multicolumn{9}{|l|}{ Yaralanmadan Ameliyata Kadar Geçen Süre } \\
\hline$<17$ gün & 7.4/ iyi & $\mathrm{p}=0.349$ & $\% 73$ & $\mathrm{p}=0.350$ & $\% 90.4$ & $\mathrm{p}=0.355$ & 7.9 & $\mathrm{p}=0.579$ \\
\hline$\geq 17$ gün & $7.9 /$ iyi & & $\% 70.4$ & & $\% 85$ & & 7.7 & \\
\hline \multicolumn{9}{|l|}{ Yaş } \\
\hline$<34$ yaş & $6.5 /$ çok iyi & $\mathrm{p}=0.004 *$ & $\% 81$ & $\mathrm{p}=0.441$ & $\% 85$ & $\mathrm{p}=0.479$ & 8.3 & $\mathrm{p}=0.6$ \\
\hline$\geq 34$ yaş & $9.8 /$ iyi & & $\% 69$ & & $\% 73$ & & 7.1 & \\
\hline \multicolumn{9}{|l|}{ Yaralanma şekli } \\
\hline - $\quad$ Temiz kesi & 6.6/ çok iyi & $\mathbf{p}<0.001 *$ & $\% 79$ & $\mathrm{p}=0.003 *$ & $\% 98$ & $\mathrm{p}=0.002 *$ & 7.9 & $\mathbf{p}<0.001 *$ \\
\hline - $\quad$ Ezilme yaralanmasi & 10.2/ iyi & & $\% 66$ & & $\% 73$ & & 6.2 & \\
\hline
\end{tabular}

diskriminasyon testinde anlamlı olarak $(p<0.001)$ bozulmaya sebep olduğu görüldü. Hastalar takip süresine göre 12 aydan uzun ve kısa olmak üzere iki gruba ayrıldı. Hasta takip süresinin iyileşme üzerinde anlamlı etkisi olmadığı görüldü. Ameliyat ile yaralanma arasında geçen sürenin iyileşmeye etkisini araştırma için 17 gün medyan değer olarak alındı ve primer-geç primer onarım ile sekonder onarım karşılaştırıldı. Ameliyat ile yaralanma arasında geçen sürenin istatistiksel olarak iyileşmeyi etkilemediği görüldü. Hasta yaşının sinir iyileşmesindeki etkisini araştırmak için 34 yaş medyan değer olarak alınıp hastalar karşılaştırıldı. Hasta yaşı artıkça iki nokta diskriminasyon testinde anlamlı $(\mathrm{p}=0.004)$ olarak bozulma olduğu görüldü. Yine yaralanma şeklinin iyileşme üzerine etkili olduğu ve ezilme yaralanmalarında iki nokta diskriminasyon testinde $(\mathrm{p}<0.001)$, monofilament testinde $(p=0.003)$, diyapazon testinde $(p=0.002)$ ve ten testinde $(\mathrm{p}<0.001)$ daha kötü sonuçlara neden olduğu saptandı. İyileşmeyi etkileyen faktörlerin detayı Tablo 2'de verilmiştir.

\section{Tartışma}

Dijital sinir yaralanmaları en sık karşılaşılan periferik sinir yaralanmaları olup el cerrahisi pratiğinde geniş bir yer kaplamaktadır. Duyu taşıma görevinin yanı sıra elin ince motor hareketlerinde de önemli rolü bulunmaktadır bu nedenle dijital sinir yaralanmaları beraberinde el fonksiyon kaybını da getirmektedir. Çalışmamızdaki en önemli bulgu dijital sinir tamirlerinin genel olarak iyi sonuçlar verdiği, ek yaralanma miktarının artmasının, ileri yaşın, sigara içmenin ve ezilme yaralanmasına maruz kalmanın iyileşmeyi olumsuz etkilediğidir.

Dijital sinir yaralanmalarının en sik olarak 3. 4 . dekattaki erkek hastalarda görüldüğü bildirilmiştir $(6,7)$. Çalışmamızda hastaların yaş ortalaması 31.7 , $\% 78$ 'i erkek ve \%81'i 3.-4. dekat yaş grubunda idi. Hem mevcut çalışma hem de literatür dijital sinir hasarına en çok maruz kalan grubun çalışan erkekler olduğunu göstermektedir. Yaralanmalarının birçoğunun (67\%) non-dominant elde olduğu saptand. Hastaların dominant elleri ile kesici aleti tutup diğer ellerini yaraladıklarını düşünüyoruz. Epidemiyolojik faktörlerin iyileşme ile ilişkisi değerlendirildiğinde, hastanın cinsiyetinin, elin dominant veya non-dominant olmasinin ve yaralanan sinirin lokalizasyonunun iyileşmeyi etkilemediğini gördük. Literatürdeki benzer çalışmalarda yine hastanın cinsiyetinin ve yaralanan sinirin ulnar veya median sinir kökenli olmasının iyileşmeyi etkilemediği gösterilmiştir (8-10). Kallio ve arkadaşları ise yaptıkları çalışmada başparmaktaki dijital sinir yaralanmalarının küçük 
parmağa göre daha iyi iyileştiğini belirtmişlerdir (11). Hastanın yaşı dışındaki epidemiyolojik özelliklerin iyileşme üzerinde etkisi olmadığını düşünüyoruz.

Çalışmamızda sinir iyileşmesinin değerlendirilmesinde temel olarak iki nokta diskriminasyon testi kullanılıştır. Literatürde bu testin sinir iyileşmenin değerlendirilmesinde kolay uygulanabilir ve güvenilir bir yöntem olduğu bildirilmiştir (12-14). Çalışmamızda sinir onarımlarının \%84.9'unda $(\mathrm{n}=62)$ iki nokta diskriminasyon testine göre iyi ve çok iyi olarak değerlendirilmiştir. Benzer çalışmalarda bu oran $\% 72$ ile $\% 90$ arasında bildirilmiștir (15-18). Hem literatür hem de mevcut çalışma dijital sinir tamirlerinin iyi sonuçlar verdiğini göstermiştir. Dijital sinir tamir sonuçlarının tatminkâr olmasında hedef organa yakınlığın ve izole duyu siniri taşımasının etkili olduğunu düşünüyoruz.

Takip süresinin özellikle proksimal sinir yaralanmalarında iyileşmeyi etkileyen bir faktör olduğu değerlendirilmektedir. Çalışmamızda medyan takip süresi 12 ay olarak alıp incelendiğinde takip süresi ile iyileşme arasında bir ilişki saptamadik. Sullivan dijital sinir iyileşmesi için 6 ayın yeterli olduğu ve bu süreden sonra daha fazla iyileşmenin görülmeyeceğini belirtmiştir (19). Mermans ve arkadaşları ise takip süresinin uzamasının dijital sinir iyileşmesini pozitif etkilediğini belirtirken Weinzweig ve arkadaşları bunun tam tersini beyan etmişleridir $(9,20)$. Proksimal sinir iyileşmesinde takip süresinin önemli olduğunu düşünmekle birlikte üst ekstremitenin en distal siniri olan dijital sinirlerin hedef organ yakınlıkları nedeniyle takip süresinin çok uzamasının sonucu değiştirmeyeceği düşüncesindeyiz.

Dijital sinir yaralanmalarına çoğu zaman tendon, kemik ve total ampütasyon gibi diğer doku yaralanmaları da eşlik etmektedir. Çalışmamızda izole sinir yaralanmalarından total ampütasyona doğru gidildikçe iyileşme parametrelerinde azalma olmakla birlikte diyapazon testi dişında bu azalmanın istatistiksel olarak bir fark yaratmadığını gördük. Weinzweig sadece kemik kırıklarının eşlik etmesi durumunda iyileşmenin kötü etkilendiğini bildirmiştir (8). Çalışmamızda iki nokta diskriminasyon ve monofilament testi gibi objektif testlerde eşlik eden yaralanma ve iyileşme arasında fark gösterilemezken diyapazon testinde fark çıkmasının bu testin sübjektifliğinden kaynaklandığını düşünüyoruz. Yine çalışmamızda yaralanma şeklinin iyileşme üzerine etkisine bakıldığında ezilme yaralanmalarında temiz kesilere göre anlamı olarak iyileşmenin bozulduğunu gözlemledik. Efstathopoulos, Al-Ghazal ve Berger yaptıkları çalışmalarında mevcut çalışmamızın bulgularına benzer çıkarımlar yapmışlar ve eşlik eden yaralanmanın iyileşme üzerine etkisi olmadığını fakat yaralanma şeklinin iyileşmeye etkisi olduğunu beyan etmişlerdir $(15,21,22)$. Ezilme yaralanmalarında doku hasar şiddetinin artmasının iyileşmeyi olumsuz etkilediğini düşünüyoruz.

Sigara içme alışkanlığının kas iskelet sistemindeki iyileşme üzerine olumsuz etkileri bilinmektedir. Çalışmamızda sigara içme alışkanlığı olan hastaların iki nokta diskriminasyon testi sonuçlarının istatistiksel olarak daha kötü olduğu görüldü. Literatürde hem dijital sinir iyileşmesinin hem de üst ekstremite sinir iyileşmesinin sigara içme alışkanlığı ile bozulduğu hem klinik hem de deneysel çalışmalar ile gösterilmiştir (21,23-25). Sigaranın mikroanjiyopatiye neden olarak iyileşme için gerekli olan öncü hücrelerin yaralanma bölgesine göçünü yavaşlatarak iyileşmeyi olumsuz etkilediğini düşünüyoruz.

Vücuttaki tüm dokularda rejenerasyon kapasitesi yaş ile ilişkilidir ve yaş ilerledikçe bu kapasite azalır. Yaşın dijital sinir iyileşmesindeki etkisini araştırmak için 34 yaş medyan olarak alıp incelediğimizde yaş ile iki nokta diskriminasyon testi sonuçları arasında anlamlı ilişki sağladık. Genç hastalarda sinir iyileşmesinin daha iyi olduğunu gördük. Weinzweig, Mailänder ve Chaise yaptıkları çalışmada yaşın dijital sinir iyileşmesini etkileyen önemli bir faktör olduğunu ve yaşlanma ile birlikte iyileşmenin azaldığını belirtmişlerdir $(9,13,17)$. Efstathopoulos ise dijital sinir tamiri sonrası tam iyileşmenin daha çok çocuk yaş grubunda gözlendiğini belirtmiştir (4). Segalman ve arkadaşları ise 60 yaş üstü hasta grubunda dijital sinir tamir sonuçlarını incelemiş ve iyileşmenin genç hasta popülasyonuna göre daha az olmasında rağmen yaşlı hasta grubunda da kabul edilebilir oranda iyileşme olduğunu belirtmişlerdir (26).

Sinir onarımları konusunda genel görüş primer sinir onarımlarının gecikmiş tamirlere göre daha iyi sonuç verdiği yönündedir $(27,28)$. Çalışmamızda primer ve geç primer ile sekonder tamirler karşılaştırıldığında iyileşme bakımından anlamlı bir fark bulunamamıştır. Literatürde de dijital sinirin tamirlerine bu konunun etkisi konusunda fikir birliği sağlanamamıştır. Weinzweig, Mermans ve Weber çalışmalarında lezyon yaşı ile iyileşme arasında bir fark bulamamışken, Altissimi, Wang, Walton ve Kallio gibi araştırmacılar primer tamirin iyileşme konusunda sekondere göre daha üstün olduğunu belirtmişlerdir $(8,9,11,16,20,29,30)$. Genel olarak uç uça dijital sinir onarımı yapılan hastalarda primer tamir üstün sonuç verirken sinir grefti ve kondiut ile tamir yapılan çalışmalarda primer ve sekonder tamir arasında fark çıkmamıştır. Bu durum, gecikmeye bağlı gelişen retraksiyonun tamir hattında oluşturduğu gerginliğin, lezyonun yaşından daha fazla iyileşmeyi etkilediğini düşündürmektedir. Çalışmamızda primer ve sekonder tamirler arasında fark çıkmamasının nedeninin ise ortalama tamir süremizin kısalığından (ortalama: 7,9 aralık: 1-49 gün) kaynaklandığını düşünüyoruz. Temiz bir yaralanmadan sonra ya hemen onarımın yapılmasını 
ya da ideal şartların oluşturulduğu en erken zamanda cerrahinin yapılması gerektiğini düşünüyoruz.

Çalışmamızın birkaç tane limitasyonu vardır. Birinci olarak mevcut çalışma retrospektiftir olarak yapılmıştır, prospektif çalışmaların sonuçlarına göre daha kesin yargilara varılabilir. İkinci olarak tüm cerrahiler aynı cerrah tarafından yapılmamıștır. Aynı cerrah tarafindan yapilan tamirlerin değerlendirilmesi ile cerrahi tekniğe bağlı doğabilecek farklılıklar ortadan kaldırılabilir. Sonuncu olarak hasta grubumuz heterojendir. Daha homojen hasta grupları ile yapılan çalışmalar farklı çıkarımlara sebep olabilir.

Sonuç olarak çalıșmamızda yaşın, sigara kullanımının ve yaralanma tipinin dijital sinir tamir sonuçlarını etkileyen faktörler olduğunu saptadık. Yaş dişında kalan epidemiyolojik özelliklerin, ameliyatta kadar geçen sürenin, takip süresinin, eşlik eden diğer el yaralanmalarının ve yaralanmanın olduğu parmağın iyileşme üzerine anlamlı bir etkisi olmadığını saptadık. Değerlendirme sonuçlarımıza göre dijital sinir tamirleri yüksek iyileşme potansiyeli ile tatminkâr sonuçlar vermektedir.

Etik Kurul Onayı: İstanbul Medipol Üniversitesi Girişimsel Olmayan Klinik Araştırmalar Etik Kurulu'ndan 03.09.2020 tarih ve 675 sayılı yazı ile izin alınmıştır.

\section{Kaynaklar}

1. Lohmeyer JA, Sommer B, Siemers F, Mailänder P. Nerve injuries of the upper extremity-expected outcome and clinical examination. Plast Surg Nurs. 2009;29(2):88-93.

2. Herndon JH. Neuromas. In: Green DP. Green's Operative Hand Surgery. 1988; 1405-1423. 4th Ed. New York: Churcill-Livingstone.

3. Pedretti LW, Early MB. Occupational therapy practice skills for physical dysfunction, 5th Ed. St. Louis: Mosby, 2001.

4. Efstathopoulos D, Gerostathopoulos N, Misitzis D, Bouchlis G, Anagnostou S, Daoutis NK. Clinical assessment of primary digital nerve repair. Acta Orthop Scand Suppl. 1995;264(23):45-7.

5. Bulut T, Akgun U, Ozcan C, Unver B, Sener M. Inter- and intra-tester reliability of sensibility testing in digital nerve repair. J Hand Surg Eur Vol. 2016;41(6):621-3.

6. Young L, Wray RC, Weeks PM. A randomized prospective comparison of fascicular and epineural digital nerve repairs. Plast Reconstr Surg. 1981;68(1):89-93.

7. Calcagnotto GN, Braga Silva J. The treatment of digital nerve defects by the technique of vein conduit with nerve segment. A randomized prospective study. Chir Main. 2006;25(34):126-30.

8. Wang WZ, Crain GM, Baylis W, Tsai TM. Outcome of digital nerve injuries in adults. J Hand Surg Am. 1996;21(1):138-43

9. Weinzweig N, Chin G, Mead M, et al. Recovery of sensibility after digital neurorrhaphy: a clinical investigation of prognostic factors. Ann Plast Surg. 2000;44(6):610-7.
10. Cheng AS, Hung L, Wong JM, Lau H, Chan J. A prospective study of early tactile stimulation after digital nerve repair. Clin Orthop Relat Res. 2001;(384):169-75.

11. Kallio PK. The results of secondary repair of 254 digital nerves.J Hand Surg Br. 1993;18(3):327-30

12. Dellon AL, Mackinnon SE, Crosby PM. Reliability of twopoint discrimination measurements. J Hand Surg Am. 1987;12(5):693-6.

13. Mailänder P, Berger A, Schaller E, Ruhe K. Results of primary nerve repair in the upper extremity. Microsurgery. 1989;10(2):147-50.

14. Novak CB, Mackinnon SE, Kelly L. Correlation of two-point discrimination and hand function following median nerve injury. Ann Plast Surg. 1993;31(6):495-8.

15. Efstathopoulos D, Gerostathopoulos N, Misitzis D, Bouchlis G, Anagnostou S, Daoutis NK. Clinical assessment of primary digital nerve repair. Acta Orthop Scand Suppl. 1995;264:45-7.

16. Altissimi M, Mancini GB, Azzarà A. Results of primary repair of digital nerves. J Hand Surg Br. 1991;16(5):546-7.

17. Chaise F, Friol JP, Gaisne E. Results of emergency repair of wounds of palmar collateral nerves of the fingers. Rev Chir Orthop Reparatrice Appar Mot. 1993;79(5):393-7.

18. Risitano G, Cavallaro G, Merrino T, Coppolino S, Ruggeri F. Clinical results and thoughts on sensory nerve repair by autologous vein graft in emergency hand reconstruction. Chir Main. 2002;21(3):194-7.

19. Sullivan DJ. Results of digital neurorrhaphy in adults. J Hand Surg Br. 1985;10(1):41-4.

20. Mermans JF, Franssen BB, Serroyen J, Van der Hulst RR. Digital nerve injuries: a review of predictors of sensory recovery after microsurgical digital nerve repair. Hand (N Y). 2012;7(3):233-41

21. al-Ghazal SK, McKiernan M, Khan K, McCann J. Results of clinical assessment after primary digital nerve repair. J Hand Surg Br. 1994;19(2):255-7.

22. Berger A, Millesi H. Nerve Grafting. Clin Orthop Relat Res. 1978;(133):49-55

23. Rinker B, Liau JY. A prospective randomized study comparing woven polyglycolic acid and autogenous vein conduits for reconstruction of digital nerve gaps. J Hand Surg Am. 2011;36(5):775-81.

24. Portincasa A, Gozzo G, Parisi D, et al. Microsurgical treatment of injury to peripheral nerves in upper and lower limbs: a critical review of the last 8 years. Microsurgery. 2007;27(5):455-62.

25. Rinker B, Fink BF, Barry NG, et al. The effect of cigarette smoking on functional recovery following peripheral nerve ischemia/reperfusion injury. Microsurgery. 2011;31(1):5965.

26. Segalman KA, Cook PA, Wang BH, Theisen L. Digital neurorrhaphy after the age of 60 years. J Reconstr Microsurg. 2001;17(2):85-8

27. Seddon H. Surgical Disorders of Peripheral Nerve. 2nd Ed. London: Churchill Livingstones, 1975.

28. Birch R. Primary and Secondary Repair of Divided Peripheral Nerves. Smith Operative Surgery; The Hand .4th Ed. London: Butterworhts, 1984.

29. Weber RA, Breidenbach WC, Brown RE, Jabaley ME, Mass DP. A randomized prospective study of polyglycolic acid conduits for digital nerve reconstruction in humans. Plast Reconstr Surg. 2000;106(5):1036-45

30. Walton RL, Brown RE, Matory WE Jr, Borah GL, Dolph JL. Autogenous vein graft repair of digital nerve defects in the finger: a retrospective clinical study. Plast Reconstr Surg. 1989;84(6):944-52. 